\title{
Caso congénito de citomegalovirus en el Hospital San Ignacio
}

\author{
María Alejandra Espinosa $^{1}$, Mercedes Olaya Contreras $^{2}$
}

\section{Resumen}

Las infecciones ocurridas durante la gestación son una importante preocupación, tanto por su incidencia como por las consecuencias de secuelas y muerte que pueden traer para el recién nacido. Sin embargo, la sospecha clínica de infección por citomegalovirus en obstetricia y en pediatría no se correlaciona con la baja confirmación que se hace de la enfermedad.

En la placenta, la infección congénita por citomegalovirus (CMV) se refleja en la aparición de villitis crónica, la cual se caracteriza por infiltrado inflamatorio linfohistiocitario focal o difuso en las vellosidades. De estos casos, $80 \%$ son asintomáticos y los que tienen síntomas presentan graves déficits neurológicos, retardo del crecimiento intrauterino e, incluso, la muerte. En autopsias fetales, la presencia de inclusiones típicas por citomegalovirus hace el diagnóstico de infección por CMV.

Se presenta el caso de un óbito fetal, producto del primer embarazo de una madre adolescente sin adecuado control prenatal, y en cuya autopsia se documentó villositis crónica y la presencia de inclusiones virales en múltiples órganos, tales como vías aéreas y páncreas, con confirmación por inmunohistoquímica.

Palabras clave: infección congénita, citomegalovirus, villositis crónica.

\section{Title}

A case of congenital citomegalovirus infection in San Ignacio Hospital, Bogotá

\begin{abstract}
Infections during pregnancy are a major concern bothdue to its incidence and sequelae it might carry, including death. However, clinical suspicion of cytomegalic infection in obstetrics and pediatrics does not correlate with the low confirmation of the disease.
\end{abstract}

1 Médica, residente de segundo año de Patología, Pontificia Universidad Javeriana, Hospital Universitario San Ignacio, Bogotá, D.C., Colombia.

2 Instructora asociada, Departamento de Patología; patóloga perinatal, Pontificia Universidad Javeriana, Hospital Universitario San Ignacio, Bogotá, D.C., Colombia. 
In the placenta, congenital CMV infection produce chronic villitis which is characterized by focal or diffuse chronic inflammation of the villi. Eighty per cent of these cases are asymptomatic, and the rest appear with severe symptoms such as neurological deficits, intrauterine growth retardation, and even death. In fetal autopsies cytomegalic inclusions are typically diagnosed in CMV infection.

We report the case of a stillbirth, product of the first pregnancy of an adolescent mother without regular prenatal control, whose autopsy showed the presence of chronic villitis. Viral inclusions in multiple organs such as lungs and pancreas were present, and CMV was confirmed by inmunohistochemestry.

Key words: congenital infection, citomegalovirus, chronic villitis.

\section{Introducción}

Las infecciones congénitas transplacentarias, conocidas como TORSCH (toxoplasma, rubéola, sífilis, citomegalovirus, hepatitis, herpes, otras), constituyen un importante capítulo dentro de la Salud Pública, la Obstetricia, la Pediatría y la Patología, dada la alta mortalidad que las acompaña y las importantes secuelas que pueden tener en quienes sobreviven a ellas.

Sin embargo, con escasa frecuencia se confirma en nuestro medio una infección por citomegalovirus. La contribución que la patología puede hacer en su búsqueda, se ha visto auxiliada por nuevas técnicas, como la inmunohistoquímica específica para el virus, que en ausencia de inclusiones típicas o aun en presencia de las mismas, se constituye en una confirmación óptima.

El presente caso ilustra toda la problemática: la muerte intrauterina ines- perada de un feto, la ausencia de sospecha clínica, la carencia de antecedentes que permitieran una orientación hacia la misma, la autopsia de un feto macerado y la posibilidad de la confirmación de la infección por citomegalovirus.

\section{Reporte de caso}

Se trata del fruto de la primera gestación de una madre de 19 años, con 32 semanas de embarazo, según la fecha de última menstruación, que consultó al Servicio de Urgencias por disminución de los movimientos fetales.

En el examen físico se encontró hipertensión arterial (mayor de 160/90 $\mathrm{mm}$ de $\mathrm{Hg}$ ) asociada con proteinuria y, además, ausencia de fetocardia. Se desembarazó y se obtuvo óbito fetal.

En la autopsia se encontró un feto de sexo masculino moderadamente macerado, de $1.500 \mathrm{~g}$ (control, $1.750 \pm 494 \mathrm{~g})$, con longitud corona- 
talón de $38 \mathrm{~cm}$ (control, $43 \mathrm{~cm}$ ), longitud corona-cóccis de 27,5 cm (control, $30 \mathrm{~cm}$ ), longitud de la planta del pie derecho de $6,5 \mathrm{~cm}$ (34 semanas), longitud de la planta del pie izquierdo de $6,4 \mathrm{~cm}$, longitud de las manos de 5 $\mathrm{cm}$, perímetro cefálico de $27,5 \mathrm{~cm}$, perímetro torácico de $26 \mathrm{~cm}$ y perímetro abdominal de $25 \mathrm{~cm}$.

En el examen interno, los órganos mostraban coloración de vino oporto, con configuración externa y al corte y relación entre ellos, normales; se hizo disección completa de los mismos y se tomaron muestras histológicas. La placenta era ovoide, de $300 \mathrm{~g}$ de peso, y presentaba inserción marginal del cordón umbilical, el cual contenía tres vasos y medía 19 x $1 \mathrm{~cm}$. En la superficie materna había un material hemorrágico, coagulado, adherido en $60 \%$ de la superficie. En los cortes seriados, con espesores que variaron entre 1,3 y $2 \mathrm{~cm}$, no se encontraron lesiones macroscópicas.

En el examen microscópico del feto, se encontraron tráquea, hígado, vesícula biliar, riñones, glándulas suprarrenales, asas intestinales, timo, bazo, corazón, encéfalo y testículos, con la morfología esperada para la edad, pero con amplios cambios por lisis. En los pulmones se observó fase alveolar del desarrollo, con presencia de escamas córneas intraalveolares, hemorragia intersticial y cambios por descomposición, además de la presen- cia de neumocitos con inclusiones nucleares y citoplasmáticas atípicas, de apariencia viral.

En la placenta, las vellosidades del corion presentaban maduración irregular, con edema no hidrópico, hiperplasia de macrófagos del estroma, depósito de fibrina entre las vellosidades e infiltrado inflamatorio, tanto agudo como crónico, rico en plasmocitos. Además, había evidente depósito de sales cálcicas. Se corroboró la presencia de un hematoma retrodecidual. En las membranas ovulares, existía inflamación crónica discreta y, en el cordón umbilical, no había alteraciones.

Se practicó un estudio de inmunohistoquímica para citomegalovirus en los cortes de pulmón, el cual fue positivo para los inmunomarcadores, lo que confirmó la impresión diagnóstica de infección por CMV.

Se hicieron los diagnósticos finales de: feto masculino moderadamente macerado, de 34 semanas de gestación, aproximadamente, por biometría con infección por citomegalovirus, con compromiso de pulmón, glándula tiroides, páncreas y placenta; y placenta con villositis crónica, abruptio placentae, deciduitis crónica y eritrocitos nucleados circulantes. Los hallazgos placentarios reflejaron los cambios por la infección y por la hipertensión inducida por el embarazo. 


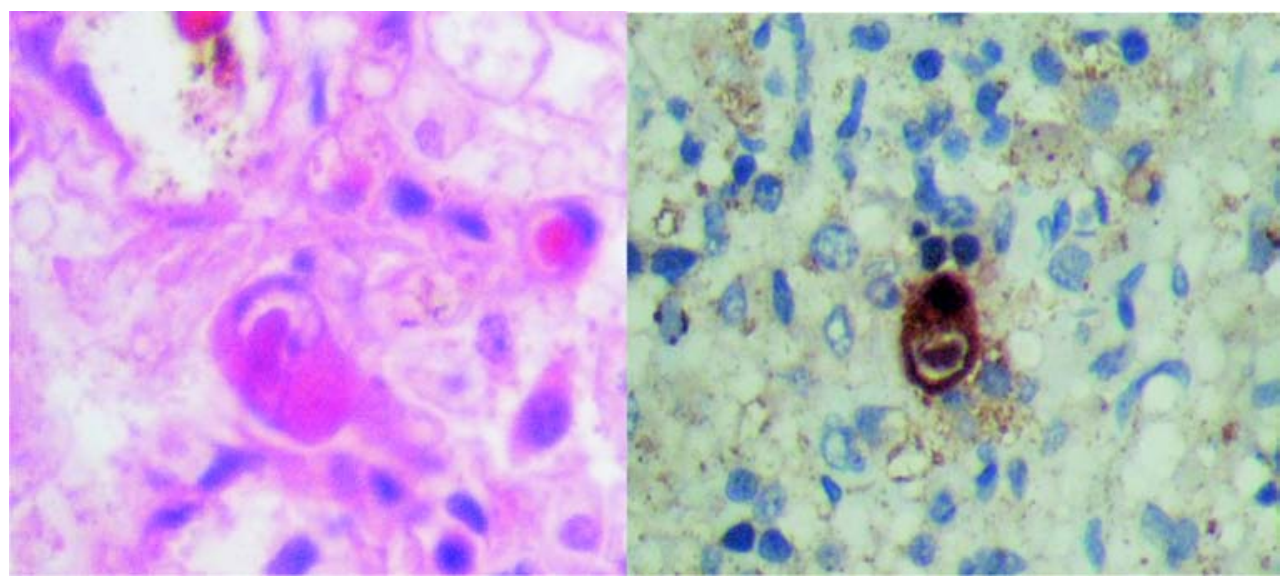

Figura 1. Inclusión sugestiva de CMV en luz alveolar. Hematoxilina-Eosina 40x.
Figura 2. Inclusión sugestiva de CMV en luz alveolar. Inmunohistoquímica positiva, 40x.

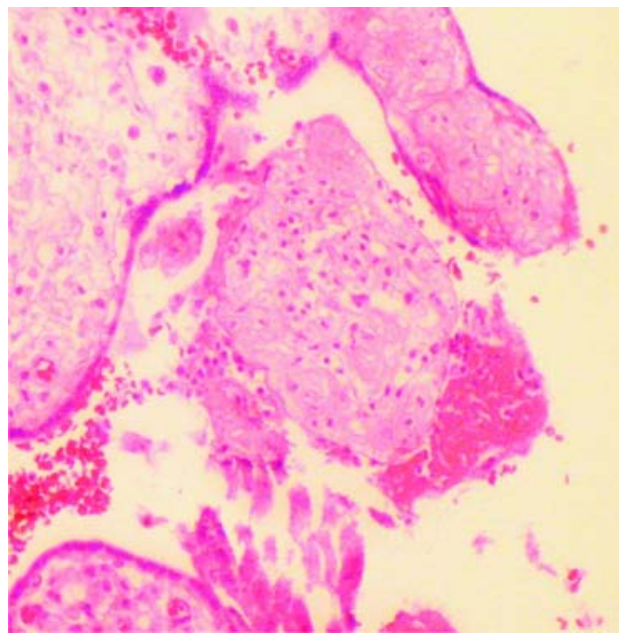

Figura 3. Villitis crónica-Infiltrado linfohistiocitario. Hematoxilina-Eosina $40 x$.

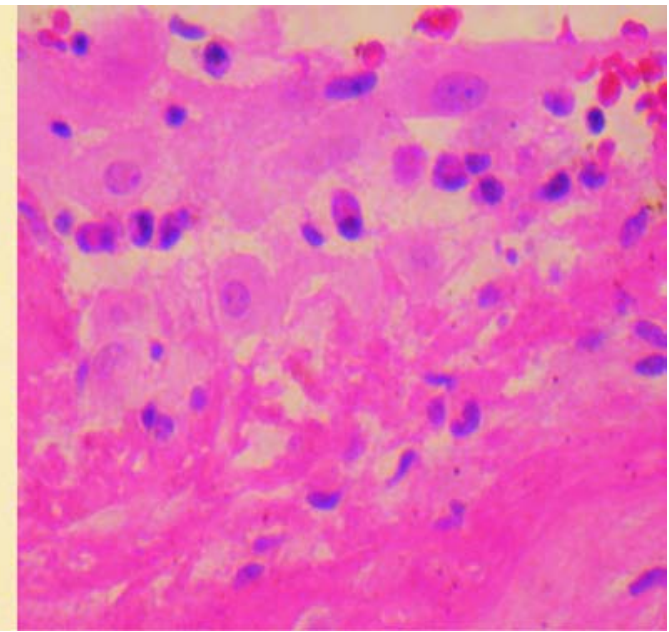

Figura 4. Deciduitis con plasmocitos. Hematoxilina-Eosina 40x. 


\section{Discusión}

El citomegalovirus es un virus ADN de doble cadena de la familia Herpes virus. En los países desarrollados, a los tres años de edad, el $80 \%$ de los niños muestran anticuerpos contra CMV adquiridos después del nacimiento y, en los adultos, la infección es de $100 \%[1]$. La seroconversión ocurre en 1 a $4 \%$ de las mujeres gestantes[2], ya que la mayoría de ellas han hecho seroconversión previa a la gestación. Estos datos se han corroborado en Colombia[3].

La infección por citomegalovirus es la principal causa de malformación congénita en los países industrializados. La infección congénita por CMV afecta entre 5 y 20 de 1.000 recién nacidos (rangos descritos entre 0,2 y 2,5\%)[1]. El virus infecta a cualquier edad, pero es mayor su adquisición en lactantes, en la infancia y en la adolescencia. En los recién nacidos, la transmisión se produce en el útero, a través de la leche materna o en el momento del parto, cuando se exponen a las secreciones vaginales[3].

La infección por el virus durante el embarazo afecta primero a la placenta, atraviesa la barrera placentaria y accede al feto. En los fetos infectados durante la gestación, se puede observar oligoamnios o polihidramnios, hydrops fetalis, restricción del creci- miento intrauterino y diversas afecciones en sus órganos, mientras que, en la placenta, el compromiso se traduce en villositis crónica.

La infección congénita es asintomática al nacimiento en 80 a $90 \%$ de los casos[2], es decir, subclínica[3]. Tales niños pueden presentar síntomas en los primeros dos años, como convulsiones y otros defectos neurológicos del desarrollo. Los niños que presentan síntomas al momento de nacer, se presentan gravemente enfermos[4]. Se afectan, principalmente, el sistema nervioso central y los órganos hematopoyéticos; en el primer caso, se puede encontrar microcefalia, calcificaciones intracerebrales, lisencefalia, hidrocefalia y calcificaciones cerebrales periventriculares con letargo, hipotonía y succión débil; y en el segundo, puede presentarse hepatitis de células gigantes, y suele haber ictericia a expensas de la bilirrubina directa, petequias, hepatoesplenomegalia, trombocitopenia y anemia.

Además, son niños que pueden ser prematuros y tener restricción del crecimiento intrauterino (más de $50 \%$ de los casos), neumonía, alteraciones oculares, como coriorretinitis, microftalmía, cataratas, nistagmo, estrabismo o atrofia óptica, y alteraciones auditivas. La mortalidad de los niños sintomáticos es de $90 \%$ y los sobrevivientes suelen tener secuelas graves. 
El cambio citopático viral puede verse en citologías urinarias, pero se ha sugerido que la prueba más sensible para detectar la infección en recién nacidos de alto riesgo es el estudio en orina o saliva para cultivo de CMV o detección con PCR[5]. Para las mujeres embarazadas, la principal fuente de contagio son los niños menores de cuatro años; además, se puede desarrollar una infección como resultado del contacto sexual[6].

En las necropsias fetales se busca el típico cambio citopático dado por una célula muy grande que contiene una única y densa inclusión basofílica rodeada de un halo perinuclear; esta inclusión se llama en "ojo de búho". Estas inclusiones citoplásmicas pueden perderse en los tejidos macerados (propios de los mortinatos)[3]. Las inclusiones pueden verse en múltiples vísceras y son comunes en páncreas, pulmón, riñón, hígado y cerebro; en este último se ven en neuronas, glía, meninges, plexos coroides y epéndimo.

Se puede reconocer afección del pulmón, que se manifiesta por infiltrado inflamatorio mononuclear intersticial, con algunas células que presentan la inclusión típica de CMV en macrófagos o en células epiteliales[7]. Sin embargo, algunas veces las células anormales no presentan las inclusiones típicas, por lo que se debe recurrir a otras pruebas para demos- trar la infección. Los estudios moleculares demuestran que la frecuencia de la infección es el doble de lo reconocido en estudios clásicos de histología[3]. Por otra parte, la villositis crónica afecta a $15 \%$ de las placentas prematuros y a término, y se define como la presencia de infiltrado linfohistiocitario en parte del árbol de las vellosidades[8].

En $90 \%$ de los casos, la etiología permanece desconocida y sólo en $10 \%$ se identifica un agente casual; esto constituye las "infecciones congénitas transplacentarias"[9]. La infección transplacentaria se produce por los microorganismos TORSCH antes mencionados, con importante frecuencia de Treponema pallidum, Citomegalovirus y Toxoplasma gondii. El parvovirus B19 y el virus de la rubéola producen otra parte importante del grupo de villositis infecciosas. Sin embargo, el CMV es el patógeno viral más frecuentemente identificado en la placenta[10] y la presencia de una sola inclusión citomegálica típica hace el diagnóstico[3]. Macroscópicamente, la apariencia de la placenta varía entre normal -se asocia con retardo del crecimiento intrauterino- y grande, pálida y edematosa -se asocia con hydrops fetalis.

En este tipo de villositis infecciosas, el compromiso de las vellosidades es difuso y puede comprometer también las membranas y el cordón 
umbilical, lo cual se puede asociar con aumento de peso de la placenta[11]. En la villositis infecciosa se observa también incremento del número de macrófagos; cuando el infiltrado inflamatorio mononuclear está dominado por células plasmáticas, sugiere en primera instancia el diagnóstico de infección por citomegalovirus[12]. Otros hallazgos importantes asociados son compromiso capilar, irregularidad en la maduración de las vellosidades y presencia de normoblastos circulantes.

Los hallazgos que sugieren infección por citomegalovirus son depósitos de hemosiderina, necrosis de las vellosidades y vasculitis; además, se encuentran inclusiones virales, sobre todo en las células endoteliales, pero también en el amnios y la decidua, y asociación con fibrosis y mineralización de las vellosidades[13].

Se considera que la infección placentaria por CMV está subdiagnosticada, ya que pueden verse calcificaciones limitadas al citotrofoblasto de la vellosidad con vasculitis linfocítica necrosante, lo cual es muy sugestivo de esta infección, pero puede ser sutil; además, la inmunohistoquímica puede ser negativa si hay menos de 20 copias del gen viral[3]. La villositis crónica, finalmente, se traduce en partos prematuros, complicaciones neurológicas y óbitos fetales[14].

Ésta y las demás infecciones por TORSCH, tienen incluso cabida en la medicina forense, porque suelen no poder sospecharse durante el embarazo y se manifiestan como un súbito óbito fetal o una muerte neonatal inesperada, que hace que los familiares instauren demandas contra las instituciones donde ha nacido su hijo.

Para los casos adquiridos de manera posnatal, la infección se transmite por medio de los linfocitos provenientes de la leche materna. Eventualmente, pueden reconocerse, además, infecciones hospitalarias en niños que reciben transfusiones. Las manifestaciones de estas infecciones son menos graves que las vistas en la forma congénita y se traducen en neumonitis, hepatomegalia, esplenomegalia y linfadenopatía.

En Colombia, en un estudio se reportaron anticuerpos positivos contra CMV en el líquido amniótico y en el suero materno (dos y tres pacientes respectivamente, de 14 pacientes participantes), en mujeres gestantes que presentaron amenaza de parto prematuro[15]. Asimismo, en un estudio de recién nacidos con bajo peso, se observó una incidencia como la reportada en otros sitios[16]; además, se encontró útil seleccionar los niños con bajo peso en búsqueda de las infecciones transplacentarias. La infección por CMV y las otras entidades TORSCH, se han asociado con preeclampsia; se cree que, como parte de los daños ocasionados a la placenta por la infección, se afectan los 
cambios normales de las arterias en espiral, lo cual favorece el desarrollo de preeclampsia[17].

El presente caso reúne las condiciones de parto prematuro, mortinato y preeclampsia materna, y además, ilustra la situación relativamente común de presentación de óbito fetal con causa desconocida. El obstetra puede no obtener mayor información sobre el caso al recibir una gestante remitida con óbito fetal, a quien atiende por única vez.

En el estudio anatomopatológico, se debe aportar a la familia información que le permita entender el doloroso suceso que vive. El patólogo en entrenamiento se enfrenta a un cuerpo que presenta signos de muerte intrauterina (maceración); una primera observación macroscópica exterior e interior no aporta mayores datos y hace complicado el examen, dada la coloración homogénea de los órganos y su consistencia friable, lo que dificulta la disección y la interpretación de los hallazgos. Posteriormente, en el estudio de histología, la lisis de todos los órganos -que incluso dificulta reconocerlos- puede no brindar información, lo que hace que en muchos casos pensemos pesimistamente sobre la utilidad del procedimiento.

Casos como éste, que sorprende con la confirmación de la inclusión viral y el aporte de información a la familia, a la sociedad y al hospital, estimulan a continuar buscando los casos en que sea posible conocer la etiología de estas muertes neonatales y de las villositis crónicas. Se espera que el diagnóstico específico de esta última se incremente, al menos, a $10 \%$ de todas las inflamaciones crónicas de las placentas que lleguen a nuestro hospital.

\section{Bibliografía}

1. Masterton R. Infection in pregnancy and the neonatal period. In: Keeling J, editor. Fetal and neonatal pathology. 3rd ed. London: Springer; 2001;32347.

2. Ornoy A, Diav-Citrin O. Fetal effects of primary and secondary cytomegalovirus infection in pregnancy. Reprod Toxicol. 2006;21:399-409.

3. Cardona N, Gaviria M, Uribe G, Jaramillo C. Anticuerpos contra los agentes del síndrome TORCHS en el grupo de gestantes de Medellín, Colombia. CES Med. 1987;1:27-31.

4. Anderson V. Infectious diseases. In: Gilbert-Barness E, editor. Potter's Pathology of the fetus, infant and child. Second edition. Philadelphia: Mosby Elsevier; 2007;401-38.

5. De Albuquerque E. Cuadro clínico, laboratorial e radiológico das infecções hematogênicas no recém- nascido e suas manifestações tardias. En: Bittencourt A, editor. Infecções congênitas transplacentárias. Primera edición. Bahia: Revinter; 1995;151-80.

6. Zakyieh A, Fawza M, Nagwa A. Is low birth weight a risk indicator for con- 
genital cytomegalovirus infection? $J$ Infect Dev Ctries. 2010;4:44-7.

7. Camus F, Hubinot C, Bernard P. Infecciones virales. En: Gratacós E, Gómez R, Nicolaides K, Rometo R, Cabero L, editores. Medicina fetal. Primera edición. Madrid: Panamericana; 2007;535-58.

8. Gould S. The respiratory system. In: Keeling J, editor. Fetal and neonatal pathology. Third edition. London: Springer; 2001;441-70.

9. Greco MA. Phenotype of villous stromal cells in placentas with cytomegalovirus, syphilis, and nonspecific villitis. Am J Pathol. 1992;141:835-42.

10. Rawlinson W. Viruses and other infections in stillbirth: what is the evidence and what should we be doing? Pathology. 2008;40:149-60.

11. Khohg T. The placenta and umbilical cord. In: Keeling J, editor. Fetal and neonatal pathology. 3rd ed. London: Springer; 2001;47-92.

12. Roberts DJ. Placental pathology, a survival guide. Arch Pathol Lab Med. 2008;132:641-51.

13. La Torre R. Placental enlargement in women with primary maternal cytomegalovirus infection is associated with fetal and neonatal disease. CID. 2006;43:1001-3.

14. Kraus FT, Redline R, Gersell D, Nelson $\mathrm{M}$, Dicke J. Inflammation and infection.
Placental pathology. First edition. Washington, D.C.: American Registry of Pathology, Atlas of non-tumor pathology. First series, Fascicle 3; 2004;75-115.

15. Venkatesh S. Non-immune hydrops fetalis and fulminant fatal disease due to congenital cytomegalovirus infection in a premature infant. $J$ Perinatol. 2005;25:608-11.

16. Alfonso W, Carrillo M, Jaramillo A, Sarmiento A. Chlamydia trachomatis, Citomegalovirus y herpes simple en suero y líquido amniótico de pacientes atendidas con amenaza de parto pretérmino. Fecha de consulta: Mayo 2 de 2010. Disponible en: http://www. encolombia.com/medicina/ginecologia/ obstetricia51400resumenes3.htm.

17. Bermúdez A, González N, Ching R. Uso del bajo peso al nacer como criterio seleccionado para la vigilancia rutinaria de anomalías congénitas de origen infeccioso. Colombia Médica. Abril-Junio: 2008;39(2) (Supl 2), 248.

18. Páez M, Serrano N, Barzilai O, Ram M, Anaya J, Shoenfeld Y. Infección por citomegalovirus y virus de EpsteinBarr en pacientes con preeclampsia. Resúmenes de trabajos libres. V Congreso Mundial de Perinatología y XXVI Congreso Colombiano de Obstetricia y Ginecología. Cartagena, Colombia 2008. 